\title{
ESTUDIOS ETNOBOTÁNICOS EN LA CONURBACIÓN BUENOS AIRES-LA PLATA, ARGENTINA: PRODUCTOS DE PLANTAS MEDICINALES INTRODUCIDOS POR INMIGRANTES PARAGUAYOS
}

\author{
JULIO A. HURRELL ${ }^{1}$, JEREMÍAS P. PUENTES ${ }^{1}$ \& PATRICIA M. ARENAS ${ }^{1}$
}

\begin{abstract}
Summary: Hurrell, J. A., J. P. Puentes \& P. M. Arenas. 2016. Ethnobotanical studies in Buenos Aires-La Plata conurbation, Argentina: Medicinal plant products introduced by Paraguayan immigrants. Bonplandia 25(1): 43-52.
\end{abstract}

This contribution includes partial results of a research line on Urban Ethnobotany, which studies the local knowledge about plants, their parts and derivatives in Buenos Aires-La Plata conurbation (Argentina). Medicinal plant products recently introduced in the study area by immigrants from Paraguay are included. The products correspond to ten species: Achyrocline alata ("jateí-ka'á"), Baccharis gaudichaudiana ("jaguareté-ka'á"), Cuphea lysimachioides ("ysypó-peré"), Euphorbia serpens ("tupasý-kambý"), Genipa americana ("ñandypá"), Helietta apiculata ("yvyra ovy"), Lycopodiella cernnua ("itá-potý"), Rhynchosia balansae ("urusú-he'è"), Stevia rebaudiana ("ka'áhe'é") and Victoria cruziana ("jacaré-yrupé"). For each case, their products, reference samples, assigned uses, biological activity and studied effects are indicated. The presence of the products of these species in the metropolitan area indicates an increase in local biocultural diversity of both plants and products and their associated knowledge.

Key words: Paraguayan migration, pluricultural urban context, therapeutic plant products, urban ethnobotany.

Resumen: Hurrell, J. A., J. P. Puentes \& P. M. Arenas. 2016. Estudios etnobotánicos en la conurbación Buenos Aires-La Plata, Argentina: Productos de plantas medicinales introducidos por inmigrantes paraguayos. Bonplandia 25(1): 43-52.

Este trabajo incluye resultados parciales de una línea de investigación en Etnobotánica urbana, que estudia los conocimientos locales sobre las plantas, sus partes y productos derivados en la conurbación Buenos Aires-La Plata. Se incluyen productos de plantas medicinales de reciente ingreso en el área de estudio a través de inmigrantes oriundos de Paraguay. Los productos corresponden a 10 especies: Achyrocline alata ("jateí-ka'á"), Baccharis gaudichaudiana ("jaguareté-ka'á"), Cuphea lysimachioides ("ysypó-peré"), Euphorbia serpens ("tupasý-kambý"), Genipa americana ("ñandypá"), Helietta apiculata ("yvyra ovy"), Lycopodiella cernnua ("itápotý"), Rhynchosia balansae ("urusú-he'ě"), Stevia rebaudiana ("ka'á-he'ě") y Victoria cruziana ("jacaré-yrupé"). Para cada caso se indican sus productos, muestras de referencia, usos asignados, actividad biológica y efectos estudiados. La presencia de los productos de estas especies en el área metropolitana indica un aumento de la diversidad biocultural local, tanto de plantas y productos como de sus conocimientos asociados.

Palabras clave: Contexto pluricultural urbano, etnobotánica urbana, migración paraguaya, productos vegetales terapéuticos.

${ }^{1}$ Laboratorio de Etnobotánica y Botánica Aplicada (LEBA), Facultad de Ciencias Naturales y Museo, Universidad Nacional de La Plata, Calle 64 nro. 3, 1900, La Plata, Buenos Aires. CONICET, Argentina. E-mail: juliohurrell@gmail.com 


\section{Introducción}

Esta contribución registra por primera vez para la conurbación Buenos Aires-La Plata, Argentina, la presencia de productos vegetales terapéuticos recientemente introducidos por inmigrantes paraguayos. Estos productos corresponden a 10 especies de plantas de la medicina popular paraguaya, en su mayoría también utilizadas en la Argentina, pero no conocidas en los circuitos comerciales del área en estudio.

El trabajo se enmarca en una línea de investigación en Etnobotánica urbana desarrollada por el Laboratorio de Etnobotánica y Botánica Aplicada (LEBA), FCNyM, UNLP. En las investigaciones en curso se asume que las extensas áreas metropolitanas son contextos pluriculturales complejos, donde el conocimiento botánico local es un corpus diverso de saberes y creencias acerca de los elementos vegetales del entorno: las plantas, partes de las mismas y sus distintos productos derivados.

En el escenario urbano, el conocimiento botánico involucra dos tipos de conocimientos que interactúan de modo diverso. Por un lado, conocimientos no tradicionales, como los conocimientos enseñados y aprendidos en escuelas y academias, incluso el científico, y los saberes difundidos por los medios masivos de comunicación. Por otro lado, conocimientos ligados a tradiciones que provienen tanto de tradiciones familiares locales de larga data, como de diversas tradiciones de origen de distintos segmentos de inmigrantes. El conocimiento botánico se corporiza en acciones, como las estrategias de selección y uso de los elementos vegetales, y dado que dicho conocimiento no es accesible de forma directa, una forma posible de aproximarse a aquellos es basar el análisis de los saberes locales en la difusión de los productos vegetales en los circuitos comerciales del área de estudio (Hurrell, 2014; Hurrell \& Pochettino, 2014).

Los segmentos de inmigrantes de diverso origen incorporan al ámbito urbano sus propios elementos vegetales, así como sus saberes asociados (sobre los usos asignados y los modos de empleo, entre otros). Una vez incorporados, algunos productos vegetales persisten dentro del circuito restringido de los inmigrantes y resultan "invisibles" para la mayoría de la población local. En este planteo, los saberes asociados corresponden al contexto de los conocimientos ligados a tradiciones. Otros productos vegetales que incorporan los inmigrantes logran expandirse al circuito comercial general y devienen "visibles". Los saberes ligados a tradiciones de estos productos ingresan al contexto de los conocimientos no tradicionales. El pasaje del circuito comercial restringido (inmigrantes) al circuito comercial general es un proceso de "visualización" que, por lo general, es potenciado por los medios de comunicación (en especial, Internet), que difunden los saberes de forma rápida $\mathrm{y}$ masiva (Hurrell, 2014). Este marco teóricometodológico ha sido aplicado en el área de estudio y ha demostrado su eficacia, con resultados interesantes para la Etnobotánica urbana. Hasta el momento, se han evaluado los elementos vegetales introducidos a través de los segmentos de inmigrantes bolivianos y chinos, considerados como grupos de referencia (Arenas et al., 2011, 2015; Hurrell et al., 2013, 2015a, b; Hurrell \& Puentes, 2013; Hurrell \& Pochettino, 2014; Hurrell, 2015; Puentes \& Hurrell, 2015).

El objetivo de esta contribución es presentar los datos preliminares obtenidos en la línea de investigación del LEBA sobre productos vegetales terapéuticos introducidos por inmigrantes oriundos de Paraguay. Se considera relevante indicar esta presencia en el escenario urbano local, para evaluar en el futuro próximo la dinámica de la circulación de los productos en los circuitos comerciales locales, así como la transmisión de sus saberes asociados en el contexto pluricultural urbano.

\section{Área de estudio e inmigrantes paraguayos}

La conurbación Buenos Aires-La Plata comprende dos aglomerados urbanos contiguos. El más extenso es el Gran Buenos Aires, que incluye la Ciudad Autónoma de Buenos Aires, la capital del país, y los partidos vecinos de la provincia de Buenos Aires. Según el Censo Nacional 2010, comprende unos 13 millones de habitantes en 3850 kilómetros cuadrados (INDEC, 2016). La ciudad de Buenos Aires presenta cerca de 3 millones de personas 
en sólo 203 kilómetros cuadrados. Este aglomerado urbano es el mayor en superficie y población de la Argentina, el segundo en Sudamérica, el tercero en Latinoamérica, el quinto en América y el decimoséptimo del mundo (Forstall et al., 2009). El otro aglomerado es el Gran La Plata, que incluye la ciudad de La Plata, capital de la provincia de Buenos Aires, el partido homónimo y los partidos vecinos de Ensenada y Berisso. Según el Censo 2010, presenta unos 800.000 habitantes en 1150 kilómetros cuadrados. Así, la población total de la conurbación es de unos 13.800.00 habitantes, y la superficie total de 5000 kilómetros cuadrados (Hurrell et al., 2011, 2013, 2015b; Puentes \& Hurrell, 2015; INDEC, 2016).

Como evidencia el análisis de los flujos migratorios durante el último siglo, la conurbación Buenos Aires-La Plata ha sido el ámbito privilegiado de recepción de la inmigración reciente en la Argentina (Marcos \& Mera, 2015). Por ejemplo, a principios del siglo $\mathrm{XX}$, los inmigrantes paraguayos se asentaron mayormente en las provincias de Formosa y Misiones, y sólo una minoría alcanzó en ese entonces la conurbación Buenos Aires-La Plata. Hacia principios del siglo XXI, la situación se invirtió: el $80 \%$ de los inmigrantes paraguayos se asentaron en el área metropolitana, mientras el 6\% lo hizo en Formosa y el $8 \%$ en Misiones (Cerrutti, 2009). Así mismo, nueve de cada diez jefes y jefas de hogar paraguayos que emigraron hacia la Argentina con posterioridad a 1980 lo hicieron directamente a Buenos Aires, buscando mejores oportunidades laborales (Cerrutti \& Parrado, 2002).

Según los datos de los Censos Nacionales de Población y Vivienda, la inmigración paraguaya en la Argentina creció de unos 262.800 a cerca de 325.000 personas entre 1980 y 2001. En 2001, el segmento de inmigrantes paraguayos se ubicó en el primer lugar en cuanto a cantidad de inmigrantes en la Argentina, seguido de los segmentos: boliviano (unas 233.500 personas), italiano (216.700), chileno (212.400) y español (134.400). En 1980 la situación era distinta: el italiano ocupaba el primer lugar (488.300), el español el segundo (374.000), y en tercer lugar el paraguayo (Cerrutti, 2009; INDEC, 2016).
Respecto de los inmigrantes de países vecinos, los bolivianos tuvieron un comportamiento similar al de la inmigración paraguaya: antes se establecieron en las provincias del Noroeste argentino, y más recientemente la mayor concentración corresponde a la conurbación Buenos Aires-La Plata (Benencia, 2008; Cerrutti, 2009; Pochettino et al., 2012).

En 2010, el segmento de inmigrantes paraguayos conservó su primer lugar respecto de los contingentes extranjeros en la Argentina, con unas 550.700 personas. Casi el $86 \%$ de la población inmigrante paraguaya en nuestro país (cerca de 473.600 personas) se concentraba en la Ciudad Autónoma de Buenos Aires y en los partidos próximos de la provincia de Buenos Aires (Bruno, 2013). Es interesante destacar que, de acuerdo con proyecciones realizadas por la Dirección General de Estadísticas, Encuestas y Censos de Paraguay para 2016, la población aproximada de Asunción, la ciudad capital y la más poblada de Paraguay, sería de unos 525.300 habitantes. Este dato, comparado con los 473.600 de la conurbación Buenos Aires-La Plata en 2010, hace significativa la presencia de la comunidad paraguaya local, sobre todo, en términos de impacto cultural.

Hacia el interior de la conurbación, los inmigrantes paraguayos se han distribuido de forma desigual en el espacio local; se encuentran fundamentalmente en el sur y este de la ciudad de Buenos Aires, y en algunas áreas periféricas de localidades bonaerenses del Gran Buenos Aires, por lo general, zonas con población de bajo nivel educativo y donde se localizan asentamientos informales (Mera, 2014; Marcos \& Mera, 2015).

Los inmigrantes paraguayos mayormente se dedican a la construcción y el servicio doméstico (Bruno, 2013), por lo cual, desde un punto de vista etnobotánico, la comercialización de productos vegetales es escasa (unos pocos sitios de expendio), si se compara con la presencia de los inmigrantes bolivianos locales dedicados a ello. Estos han tenido una mayor diversificación laboral, incluidas las prácticas hortícolas en sectores periurbanos y el comercio de productos de origen vegetal. Esta última actividad tiene su máximo desarrollo en torno al mercado boliviano del barrio porteño de Liniers, un 
"mercado tradicional" enclavado en plena área metropolitana, conocido por buena parte de los pobladores locales que buscan productos alimentarios y medicinales a precios más económicos (Pochettino et al., 2012; Puentes \& Hurrell, 2015).

\section{Materiales y Métodos}

Los relevamientos etnobotánicos en la conurbación Buenos Aires-La Plata se realizan hace más de una década. La búsqueda de productos de origen vegetal en los circuitos comerciales incluyó, hasta el momento, locales del circuito comercial general, en especial, los llamados "dietéticas" (dedicados a la venta de alimentos "saludables", fitoterápicos y suplementos dietéticos), y sitios de expendio de los segmentos de inmigrantes bolivianos y chinos, previamente seleccionados como grupos de referencia. En los estudios realizados se identificó la presencia de cinco sitios de expendio de productos vegetales terapéuticos correspondientes al segmento de inmigrantes paraguayos. Estos sitios incluyeron cuatro puestos callejeros no permanentes en la Ciudad Autónoma de Buenos Aires, en los barrios de Retiro, Constitución y Liniers, y un local comercial de la ciudad de La Plata, que vende, entre otros tipos de productos, materiales de herboristería traídos de Paraguay.

Cada sitio de expendio no permanente fue visitado una vez; el local comercial, cinco veces. Se adquirió, para cada producto relevado, una muestra de referencia, una vez que se constató que se comercializaban los mismos productos. Las muestras fueron depositadas para su documentación en las colecciones etnobotánicas del LEBA. Las especies botánicas fueron identificadas mediante caracteres morfológicos externos y se consideró asimismo la información provista por las etiquetas de cada producto. Para la correcta nomenclatura de casa especie considerada se consultaron las bases de datos: The Plant List (2013), Instituto de Botánica Darwinion (2016) y Tropicos (2016).

Los relevamientos siguieron las metodologías y técnicas cualitativas usuales del trabajo etnobotánico, en particular, listados libres, entrevistas libres y semiestructuradas (Martin 1995; Blanco-Castro 1996; Albuquerque \& Lucena, 2004; Quinlan 2005; Stepp 2005; Etkin \& Ticktin 2010). Previo consentimiento informado, se entrevistaron 10 informantes calificados de ambos sexos, entre 25 y 55 años de edad, en su mayoría, vendedores que demostraron su conocimiento sobre las propiedades de los elementos vegetales que expenden y orientan a los consumidores acerca de sus formas de empleo y de administración. La información obtenida en los relevamientos se comparó con los usos asignados para las mismas especies en otras fuentes: bibliografía específica (Basualdo \& Soria, 1996, 2014; Cáceres \& Singer, 2001; Basualdo et al., 2004; González Torres, 2005; Scavone, 2011; Degen de Arrúa \& González, 2014) y datos de internet, en especial el sitio http://www.portalguarani.com, dado que constituye una fuente de información muy consultada por diversos pobladores urbanos y que orienta la selección de los productos a consumir (Hurrell, 2014, 2015; Hurrell et al., 2015a).

Según los protocolos de la línea de investigación en Etnobotánica urbana del LEBA, se realizó también una revisión de la bibliografía disponible para cada especie, acerca de sus efectos y actividad biológica, que permitió evaluar el estado de los conocimientos académicos en relación con los usos localmente asignados.

\section{Resultados}

LaTabla 1 presentalos productos terapéuticos correspondientes a diez especies de plantas que expenden inmigrantes paraguayos en los sitios de expendio relevados. En la mayoría de estos sitios se constató la presencia de estas diez especies y los informantes comentaron que, en ocasiones, traen otros productos correspondientes a otras especies, que se espera relevar en el futuro. En la tabla se indican las especies por orden alfabético, familia botánica, los nombres vernáculos en guaraní (en negrita) y en español, el tipo de producto y la muestra respectiva, los usos en la medicina popular paraguaya y la actividad 
biológica y efectos estudiados.

Todos los productos son materiales secos con distinto grado de fragmentación (tallos, hojas, flores, cortezas, xilopodios, raíces) y envasados, la mayoría identificados en las etiquetas por su nombre guaraní.

Tabla 1. Productos de plantas medicinales introducidos por inmigrantes paraguayos en la conurbación Buenos AiresLa Plata, Argentina.

\begin{tabular}{|c|c|c|}
\hline $\begin{array}{c}\text { Especies, familias, nombres } \\
\text { vernáculos, productos [muestras] }\end{array}$ & $\begin{array}{l}\text { Usos en la medicina popular } \\
\text { paraguaya }\end{array}$ & $\begin{array}{c}\text { Actividad biológica y efectos } \\
\text { estudiados }\end{array}$ \\
\hline $\begin{array}{l}\text { Achyrocline alata (Kunth) DC. } \\
\text { AsTERACEAE } \\
\text { Jateí-ka'á } \\
\text { Güira-güira, marcela, marcela } \\
\text { brasilera } \\
\text { Partes aéreas fragmentadas } \\
\text { envasadas [PR000] }\end{array}$ & $\begin{array}{l}\text { Regulador del sistema } \\
\text { digestivo: indigestión, trastornos } \\
\text { gastrointestinales crónicos, gases, } \\
\text { constipación, carminativo, hepático, } \\
\text { infecciones urinarias, apendicitis, } \\
\text { antiasmático, antidiabético, } \\
\text { emenagogo, antiinflamatorio, } \\
\text { antirreumático, sedante. }\end{array}$ & $\begin{array}{l}\text { Antiproliferativo (carcinoma } \\
\text { hepatocelular) (Carraz et al., 2015), } \\
\text { antiinflamatorio (Toffoli-Kadri et } \\
\text { al., 2014), citotóxico, antifúngico } \\
\text { (Zapata et al., 2010), antimicrobiano } \\
\text { (Demarque et al., 2015), antiviral, } \\
\text { moluscicida (Barboza et al., 2009), } \\
\text { anti-tuberculosis (Bueno-Sánchez } \\
\text { et al., 2009). }\end{array}$ \\
\hline $\begin{array}{l}\text { Baccharis gaudichaudiana DC. } \\
\text { AsTERACEAE } \\
\text { Jaguareté-ka'á } \\
\text { Carqueja, chilca melosa } \\
\text { Partes aéreas secas fragmentadas } \\
\text { envasadas } \\
\text { [PR001] }\end{array}$ & $\begin{array}{l}\text { Tónico amargo, aperitivo, digestivo, } \\
\text { eupéptico, estomacal, vermífugo, } \\
\text { laxante, antidiarreico, hepático, } \\
\text { colagogo, diurético, depurativo, } \\
\text { hidropesía, anti-arteriosclerosis, } \\
\text { lepra, úlceras sifilíticas, infecciones } \\
\text { urinarias y respiratorias, } \\
\text { antiséptico, emenagogo, febrífugo, } \\
\text { antiinflamatorio. }\end{array}$ & $\begin{array}{l}\text { Citotóxico (Fullas et al., 1994), } \\
\text { antiviral (Visintini Jaime et al., } \\
\text { 2013), antileishmaniásico, } \\
\text { antioxidante (Barboza et al., 2009). }\end{array}$ \\
\hline $\begin{array}{l}\text { Cuphea lysimachioides Cham. \& } \\
\text { Schltdl. } \\
\text { LYTHRACEAE } \\
\text { Ysypó-peré } \\
\text { Siete sangrías } \\
\text { Xilopodios secos fragmentados } \\
\text { envasados [PR002] }\end{array}$ & $\begin{array}{l}\text { Antiinflamatorio, para tratar faringitis, } \\
\text { irritación y dolor de garganta, } \\
\text { amigdalitis, infecciones, vulnerario, } \\
\text { antiséptico (heridas), astringente, } \\
\text { antidiarreico. }\end{array}$ & Sin datos. \\
\hline $\begin{array}{l}\text { Euphorbia serpens Kunth } \\
\text { EUPHORBIACEAE } \\
\text { Tupasý-kambý } \\
\text { Lechetrés, meona, yerba de la } \\
\text { golondrina, yerba meona } \\
\text { Partes aéreas secas fragmentadas } \\
\text { envasadas [PR007] }\end{array}$ & $\begin{array}{l}\text { Diurético, vulnerario, antidermatósico } \\
\text { (úlceras), antiséptico, antiinflamatorio } \\
\text { (ovario), expectorante, antitumoral, } \\
\text { problemas lumbares, renales, } \\
\text { cálculos biliares, hepático, purgante, } \\
\text { antidiarreico, antioftálmico. }\end{array}$ & $\begin{array}{l}\text { Diurético (Cheruse et al., 1983; } \\
\text { Garro et al., 2014), antiviral } \\
\text { (Ruffa et al. 2004), antibacteriano } \\
\text { (Barboza et al., 2009), } \\
\text { antiespasmódico (Ahmad, 2009). }\end{array}$ \\
\hline $\begin{array}{l}\text { Genipa americana L. } \\
\text { RUBIACEAE } \\
\text { Ñandypá } \\
\text { Ñapindá, genipapo, jenipá, } \\
\text { jenipapo } \\
\text { Corteza y hojas secas fragmentadas } \\
\text { envasadas [PR003] }\end{array}$ & $\begin{array}{l}\text { Depurativo, antianémico, hipotensor, } \\
\text { tónico, diurético, purgante (raíces), } \\
\text { hepático, antiictérico, astringente, } \\
\text { antidiarreico, antirreumático, } \\
\text { vulnerario, antiséptico, antisifilítico, } \\
\text { antiasmático, antirreumático, } \\
\text { antidiabético, hipocolesterolémico, } \\
\text { adelgazante, afrodisíaco. }\end{array}$ & $\begin{array}{l}\text { Antitumoral (Ueda et al., 1991), } \\
\text { citotóxico (Fernández et al., 2011), } \\
\text { incremento del flujo biliar (Barboza } \\
\text { et al., 2009). }\end{array}$ \\
\hline $\begin{array}{l}\text { Helietta apiculata Benth. RUTACEAE } \\
\text { Yvyra ovy } \\
\text { Canela amarilla, canela de venado } \\
\text { Corteza seca fragmentada envasada } \\
\text { [PR004] }\end{array}$ & $\begin{array}{l}\text { Depurativo, reconstituyente, } \\
\text { antiparasitario, antidiabético, } \\
\text { digestivo, analgésico, dolor de } \\
\text { garganta, enfermedades de las } \\
\text { vías urinarias, próstata, afrodisíaco } \\
\text { (impotencia). }\end{array}$ & $\begin{array}{l}\text { Antibacteriano, antifúngico } \\
\text { (Frazener et al., 2007), } \\
\text { antichagásico (Ferreira et al., 2014), } \\
\text { antileishmaniásico (Ferreira et al., } \\
\text { 2010), antioxidante (Fernandes, } \\
\text { 2011), depresor potencial del } \\
\text { sistema nervioso central (Barboza } \\
\text { et al., 2009). }\end{array}$ \\
\hline
\end{tabular}




\begin{tabular}{|c|c|c|}
\hline $\begin{array}{l}\text { Especies, familias, nombres } \\
\text { vernáculos, productos [muestras] }\end{array}$ & $\begin{array}{c}\text { Usos en la medicina popular } \\
\text { paraguaya }\end{array}$ & $\begin{array}{c}\text { Actividad biológica y efectos } \\
\text { estudiados }\end{array}$ \\
\hline $\begin{array}{l}\text { Lycopodiella cernua (L.) Pic. Serm. } \\
\text { LYCOPODIACEAE } \\
\text { Itá-potý } \\
\text { Plantas secas fragmentadas } \\
\text { envasadas [PR008] }\end{array}$ & $\begin{array}{l}\text { Antiinflamatorio (riñones, vías } \\
\text { urinarias, vejiga), analgésico } \\
\text { (micción difícil y dolorosa), } \\
\text { diurético, antiséptico, vulnerario, } \\
\text { antidermatósico (úlceras), } \\
\text { enfermedades venéreas, } \\
\text { astringente, antidiarreico, digestivo, } \\
\text { antirreumático. }\end{array}$ & $\begin{array}{l}\text { Antiamnésico (Chuong et al., 2014), } \\
\text { anti-Alzheimer (Hung et al., 2015). }\end{array}$ \\
\hline $\begin{array}{l}\text { Rhynchosia balansae Micheli } \\
\text { LEGUMINOSAE } \\
\text { Urusú-he'ě } \\
\text { Raíces secas fragmentadas } \\
\text { envasadas [PR005] }\end{array}$ & $\begin{array}{l}\text { Expectorante, bronquial, anticatarral, } \\
\text { antitusivo, antigripal, resfríos, afonía, } \\
\text { febrífugo, anti-dispepsia, laxante, } \\
\text { antiinflamatorio (riñones, vías } \\
\text { urinarias, vejiga), diurético, antilítico. }\end{array}$ & Sin datos. \\
\hline $\begin{array}{l}\text { Stevia rebaudiana (Bertoni) Bertoni } \\
\text { AsTERACEAE } \\
\text { Ka'á-he'ě } \\
\text { Estevia, hierba dulce, yerba dulce, } \\
\text { yerba dulce paraguaya } \\
\text { Hojas secas fragmentadas envasadas } \\
\text { [PR009] }\end{array}$ & $\begin{array}{l}\text { Edulcorante, antidiabético, } \\
\text { adelgazante, antiinflamatorio, } \\
\text { antiartrítico, antirreumático, } \\
\text { hipotensor, cardiotónico, depurativo, } \\
\text { diurético, laxante, digestivo, antiácido, } \\
\text { emoliente, anti-estreñimiento, } \\
\text { anti-caries, antitusivo, antiséptico, } \\
\text { vulnerario, antidermatósico, } \\
\text { contraceptivo. }\end{array}$ & $\begin{array}{l}\text { Antitumoral, antioxidante, } \\
\text { hipoglucémico, hipotensor, } \\
\text { nefroprotector, antiviral, } \\
\text { antimicrobiano, contraceptivo, } \\
\text { antiinflamatorio, inmunomodulator } \\
\text { (Hurrell et Puentes, 2013; Ruiz-Ruiz } \\
\text { et al., 2015), anticonvulsivo (Di } \\
\text { lanni et al., 2015). }\end{array}$ \\
\hline $\begin{array}{l}\text { Victoria cruziana A.D. Orb. } \\
\text { NYMPHAEACEAE } \\
\text { Jacaré-yrupé } \\
\text { Irupé, victoria regia, maíz del agua } \\
\text { Hojas secas fragmentadas envasadas } \\
\text { [PR006] }\end{array}$ & $\begin{array}{l}\text { Antitusivo (tos convulsa), } \\
\text { antiasmático, expectorante, } \\
\text { anticatarral, pectoral, inflamación de } \\
\text { los bronquios. }\end{array}$ & Sin datos. \\
\hline
\end{tabular}

\section{Discusión y Conclusiones}

Las diez especies relevadas a partir de sus productos son nativas de Paraguay. Con la excepción de Stevia rebaudiana (Bertoni) Bertoni (Asteraceae), las nueve especies restantes también son nativas de la Argentina: Achyrocline alata (Kunth) DC., Baccharis gaudichaudiana DC. (Asteraceae), Cuphea lysimachioides Cham. \& Schltdl. (Lythraceae), Euphorbia serpens Kunth (Euphorbiaceae), Genipa americana L. (Rubiaceae), Helietta apiculata Benth. (Rutaceae), Lycopodiella cernua (L.) Pic. Serm. (Lycopodiaceae), Rhynchosia balansae Micheli (Leguminosae) y Victoria cruziana A.D. Orb. (Nymphaeaceae). La mayoría de estas especies se emplean en la medicina popular argentina, en distintas partes del país (Barboza et al., 2009), pero según los registros propios no se comercializan productos en el área metropolitana.
Stevia rebaudiana, introducida en cultivo en Misiones, se halla ampliamente difundida a través de distintos tipos de productos comerciales dentro de la conurbación Buenos Aires-La Plata; es decir, es una especie "visible" para el área metropolitana (Hurrell \& Puentes, 2013). Las otras nueve especies no presentan productos en el circuito comercial general, por lo tanto, son especies "invisibles" para la mayoría de la población local, que circulan sólo en el ámbito del segmento de inmigrantes paraguayos. Dado que este es el primer registro para el área metropolitana, la investigación pretende evaluar a futuro su posible "visualización", en caso de que accedan al circuito comercial general, proceso que se ha evaluado a partir de productos vegetales de los segmentos de inmigrantes bolivianos (Pochettino et al., 2012; Puentes \& Hurrell, 2015) y chinos (Hurrell, 2015). 
Dos de las especies relevadas, Achyrocline alata y Baccharis gaudichaudiana, presentan usos similares a los de otras especies difundidas en los circuitos comerciales de la conurbación, como Achyrocline satureoides (Lam.) DC., "marcela", Baccharis articulata (Lam.) Pers., B. crispa Spreng. y B. trimera (Less.) DC., "carquejas" (Hurrell \& Puentes, 2013).

Respecto del relevamiento de datos sobre efectos y actividad biológica evaluados, sólo tres especies no presentan datos en ese sentido: Cuphea lysimachioides, Rhynchosia balansae y Victoria cruziana. En contraste, Achyrocline alata, Helietta apiculata y Stevia rebaudiana son las especies mejor estudiadas, sobre todo, esta última. Para el resto de las especies sería importante promover estudios que convaliden sus usos.

Si se compara los segmentos de inmigrantes bolivianos y paraguayos, los primeros comercializan productos vegetales para su propio segmento ("invisibles") y también para el público general ("visibles"), dado que la dinámica de la difusión de productos y la transmisión de saberes asociados corresponde a un proceso de "visualización" (Hurrell, 2014). Hasta el momento, los productos vegetales que expenden los inmigrantes paraguayos permanecen dentro de su propio circuito comercial: son adquiridos principalmente por otros inmigrantes paraguayos; es decir, son "invisibles" para la mayoría de los habitantes de la conurbación. Desde el punto de vista de las especies, como se indicó antes, se excluye Stevia rebaudiana, pero es importante destacar que la "visibilidad" de esta especie en el área de estudio, en especial, como edulcorante, surge de un proceso que se origina en el contexto de los conocimientos no tradicionales (por razones básicamente comerciales), y no se debe a un proceso de visualización originado en el marco de un segmento de inmigrantes (contexto ligado a tradiciones) y luego expandido localmente en el circuito comercial general.

Finalmente, más allá del aporte de esta contribución como registro preliminar, desde ya se puede afirmar que la sola presencia de los productos vegetales mencionados para el área de estudio indica un incremento de la diversidad biocultural de la conurbación
Buenos Aires-La Plata, referida tanto a la diversidad de especies y productos derivados, como a la de sus saberes asociados, en este caso, relacionados con la medicina popular paraguaya y su posible impacto cultural en la mayor área metropolitana de la Argentina.

\section{Agradecimientos}

Los autores agradecen a la Dr. María Lelia Pochettino y los integrantes del LEBA, así como también a los informantes que participaron desinteresadamente en los trabajos de campo. La línea de investigación en Etnobotánica urbana del LEBA tiene soporte financiero de la Universidad Nacional de La Plata y del Consejo Nacional de Investigaciones Científicas y Técnicas (CONICET), Argentina.

\section{Bibliografía}

AHMAD, I. 2009. Phytochemical and biological studies of Euphorbia serpens, Euphorbia granulata (Euphorbiaceae) and Vernonia cinerascens (Compositae). 145 pp. Thesis. Faculty of Pharmacy, Bahauddin Zakariya University, Multan.

ALBUQUERQUE, U. P. \& R. F. LUCENA. 2004. Métodos e técnicas na pesquisa etnobotânica. 190 pp. Livro Rápido/NUPEEA, Recife.

ARENAS, P. M., I. CRISTINA, J. P. PUENTES, F. BUET COSTANTINO, J. A. HURRELL \& M. L. POCHETTINO. 2011. Adaptógenos: plantas medicinales tradicionales comercializadas como suplementos dietéticos en la conurbación Buenos Aires-La Plata (Argentina). Bonplandia 20: 251-264.

ARENAS, P. M., B. DOUMECQ, J. P. PUENTES, J. A. HURRELL. 2015. Algas y plantas comercializadas como adelgazantes en el Área Metropolitana de Buenos Aires, Argentina. Gaia Scientia 9: 32-40.

BARBOZA, G., J. CANTERO, C. O. NUÑEZ, A. PACCIARONI \& L. ARIZA ESPINAR. 2009. Medicinal plants: A general review and a phytochemical and ethnopharmacological screening of the native Argentine Flora. Kurtziana 34: 7-365.

BASUALDO, I. \& N. SORIA. 1996. Farmacopea Herbolaria Paraguaya: Especies de la medicina folclórica utilizadas para combatir enfermedades del aparato respiratorio (Parte 1). Rojasiana 3: 197-238.

BASUALDO, I. \& N. SORIA. 2014. Plantas medicinales comercializadas en el Mercado Municipal de la Ciudad de Pilar, Departamento Ñeembucu, Paraguay. Dominguezia 30: 47-53. 
BASUALDO, I., N. SORIA, M. ORTÍZ, \& R. DEGEN. 2004. Plantas medicinales comercializadas en los mercados de Asunción y Gran Asunción. Rojasiana 6: 95-114.

BENENCIA, R. 2008. Migrantes bolivianos en la periferia de ciudades argentinas: procesos y mecanismos tendientes a la conformación de territorios productivos y mercados de trabajo. En S. Novick (ed.), Las Migraciones en América Latina. Políticas, Culturas y Estrategias, pp. 13-30. CLACSO, Buenos Aires.

BLANCO-CASTRO, E. 1996. Ideas metodológicas relativas al trabajo de campo etnobotánico. Monogr. Jard. Bot. Córdoba (España) 3: 89-91.

BRUNO, S. F. 2013. El proceso migratorio paraguayo hacia Argentina: Evolución histórica, dinámica asociativa y caracterización sociodemográfica y laboral. En J. Gurrieri \& E. Texidó (eds.), Migrantes paraguayos en Argentina: Población, instituciones y discursos (Cuadernos Migratorios 4), pp. 11-55. Organización Internacional para las Migraciones, Buenos Aires.

BUENO-SÁNCHEZ J. G., J. R. MARTÍNEZMORALES, E. E. STASHENKO, W. RIBÓN. 2009. Anti-tubercular activity of eleven aromatic and medicinal plants occurring in Colombia. Biomedica 29: 51-60.

CÁCERES A. \& M. M. SINGER, 2001. Manual de uso de hierbas medicinales del Paraguay. $72 \mathrm{pp}$. Fundación Celestina Pérez de Almada, UNESCO, Oficina Regional de Ciencia y Tecnología para América Latina y el Caribe, Asunción.

CARRAZ, M., C. LAVERGNE, V. JULliAN, M. WRIGHT, J. E. GAIRIN, M. GONZÁLEZ DE LA CRUZ \& G. BOURDY. 2015. Antiproliferative activity and phenotypic modification induced by selected Peruvian medicinal plants on human hepatocellular carcinoma Hep3B cells. J. Ethnopharmacol. 166: 185-199.

CERRUTTI, M. 2009. Diagnóstico de las poblaciones de inmigrantes en la Argentina. 68 pp. Dirección Nacional de Población, Ministerio del Interior, Buenos Aires.

CERRUTTI, M. \& E. PARRADO. 2002. Migración laboral de paraguayos a la Argentina: Entrada a los mercados de trabajo y trayectorias ocupacionales. Estud. Migrat. Latinoam. 48: 369-399.

CHERUSE, J. J., A. N. BALDINI \& L. E. BRUNO BLANCH. 1983. Ensayo farmacodinámico preliminar de Euphorbia serpens Kunth (Euphorbiaceae). Acta Farm. Bonaerense 2: 19-22.

CHUONG, N. N., B. H. TRUNG, T. C. LUAN, T. M. HUNG, N. H. DANG \& N. T. DAT. 2014. Antiamnesic effect of alkaloid fraction from Lycopodiella cernua (L.) Pic. Serm. on scopolamine-induced memory impairment in mice. Neurosci. Lett. 575: $42-46$
DEGEN DE ARRÚA, R. \& Y. GONZÁLEZ. 2014. Plantas utilizadas en la medicina popular paraguaya como antiinflamatorias. Bol. Latinoam. Caribe Plant. Med. Aromat. 13: 213 -231.

DEMARQUE, D. P., S. M. F. FITTS, A. G. BOARETTO, J. C. LEITE DA SILVA, M. C. VIEIRA, V. N. P. FRANCO, C. B. TEIXEIRA, M. C. TOFFOLIKADRI \& C. A. CAROLLO. 2015. Optimization and technological development strategies of an antimicrobial extract from Achyrocline alata assisted by statistical design. Plos One, doi: 10.1371/journal. pone.0118574.

DI IANNI, M. E., M. E. DEL VALLE, A. V. ENRIQUE, M. A. ROSEllA, F. BRUNO, L. E. BRUNOBLANCH \& A. TALEVI. 2015. Computer-aided identification of anticonvulsant effect of natural nonnutritive sweeteners stevioside and rebaudioside A. Assay Drug Dev. Technol. 13: 313-318.

ETKIN, N. L. \& T. TICKTIN. 2010. Advancing an ethno-ecological perspective that integrates theory and method in ethnobotany. En U. P. Albuquerque \& N. Hanazaki (eds.), Recent developments and case studies in Ethnobotany, pp. 33-57. SBEE/NUPEEA, Recife.

FERNANDES, T. S. 2011. Análise fitoquímica e estudio das atividades antimicrobiana, antioxidante e inibição da enzima Acetilcolinesterase da espécie Helietta apiculata Benth. 137 pp. Dissertação de Mestrado. Universidade Federal, Santa María.

FERNÁNDEZ, V., D. FRANCO DE DIANA, D. FERNÁNDEZ, M. C. VEGA GÓMEZ, J. SEGOVIA ABREU, D. CASTIGLIONI, L. SALES, M. MARTÍNEZ, D. LÓPEZ, N. BOBADILLA, J. ALFONSO, A. MOJOLI LE QUESNE, D. MONGES \& M. VERA. 2011. Efecto antimitótico y citotóxico del extracto etanólico de Genipa americana L. sobre tejido meristematico de Allium cepa L. y cultivo celular NCTC-929. Steviana 3: 48-53.

FERREIRA M. E., A. ROJAS DE ARIAS, G. YALUFF, N. V. DE BILBAO, H. NAKAYAMA, S. TORRES, A. SCHININI, I. GUYC, H. HEINZEN \& A. FOURNET. 2010. Antileishmanial activity of furoquinolines and coumarins from Helietta apiculata. Phytomedicine 17: 375-378.

FERREIRA, M. E., H. NAKAYAMA, S. TORRES, G. YALUFF, L. SANABRIA, N. V. DE BILBAO, A. SCHININI, A. ROJAS DE ARIAS, I. GUY, H. GUINAUDEAU \& A. FOURNET. 2014. Propiedad antichagásica in vitro e in vivo de maculina aislada de Helietta apiculata Benth. (Rutaceae). Steviana 6: 5-12.

FORSTALL, R. L., R. P. GREENE \& J. B. PICK. 2009. Which are the largest? Why published lists of major urban areas vary so greatly. Tijdsch. Econ. Soc. Geogr. 100 (3): 277-297.

FRANZENER G., A. DA SILVA MARTÍNEZFRANZENER, J. R. STANGARLIN, M. P. CZEPAK, 
K. R. FREITAS SCHWAN-ESTRADA \& M. E. SILVA CRUZ. 2007. Atividades antibacteriana, antifúngica e indutora de fitoalexinas de hidrolatos de plantas medicinais. Semin. Ciênc. Agrár. 28: 29-38.

FULlAS, F., R. A. HUSSAIN, H. B. CHAI, J. M. PEZZUTO, D. D. SOEJARTO \& A. D. KINGHORN. 1994. Cytotoxic constituents of Baccharis gaudichaudiana. J. Nat. Prod. 57: 801-807.

GARRO, M. F., M. A. GETTE, M. E. PETENATtI, M. C. POPOVICH, G. CAMÍ, E. SAIDMA, L. A. DEL VITTO, E. M. PETENATTI. 2014. Caracterización por HPLC y FTIR de los extractos acuosos de tres especies diuréticas del centro-oeste argentino. Dominguezia 30: 41-45.

GONZÁLEZ TORRES, D. M. 2005. Catalogo de plantas medicinales (y alimenticias y útiles) usadas en Paraguay. 480 pp. Servilibro, Asunción.

HUNG, T. M., J. S. LEE, N. N. CHUONG, J. A. KIM, S. H. OH, M. H. WOO, J. S. CHOI \& B. S. MIN. 2015. Kinetics and molecular docking studies of cholinesterase inhibitors derived from water layer of Lycopodiella cernua (L.) Pic. Serm. II. Chem.-Biol. Interact. 240: 74-82.

HURRELL, J. A. 2014. Urban Ethnobotany in Argentina: Theoretical advances and methodological strategies. Ethnobio. Conserv. 3: 2, doi:10.15451/ec2014-63.3-1-11.

HURRELL, J. A. 2015. Dinámica del conocimiento botánico local: plantas de la Fitoterapia Tradicional China comercializadas en la ciudad de Buenos Aires (Argentina). Actas VI Congreso Internacional de Etnobotánica (ICEB 2014), Córdoba, España (en prensa).

HURRELL, J. A. \& M. L. POCHETTINO. 2014. Urban Ethnobotany: theoretical and methodological contributions. En U. P. Albuquerque, L. V. F. Cruz da Cunha, R. F. P. Lucena \& R. R. N. Alves (eds.), Methods and Techniques in Ethnobiology and Ethnoecology, pp. 293-310. Springer-Humana Press, New York.

HURRELL, J. A. \& J. P. PUENTES. 2013. Medicinal and aromatic species of Asteraceae commercialized in the conurbation Buenos Aires-La Plata (Argentina). Ethnobiology and Conservation 2:7, http:// ethnobioconservation.com/index.php/ebc/article/ view/39/36.

HURRELL, J. A., E. A. ULIBARRI, J. P. PUENTES, F. BUET COSTANTINO, P. M. ARENAS, M. L. POCHETTINO. 2011. Leguminosas medicinales y alimenticias utilizadas en la conurbación Buenos Aires-La Plata, Argentina. Bol. Latinoam. Caribe Plant Med. Aromat. 10 (5): 443-455.

HURRELL, J. A., M. L. POCHETTINO, J. P. PUENTES \& P. M. ARENAS. 2013. Del marco tradicional al escenario urbano: Plantas ancestrales devenidas suplementos dietéticos en la conurbación Buenos
Aires-La Plata, Argentina. Bol. Latinoam. Caribe Plant. Med. Aromat.12: 499-515.

HURRELL, J. A., P. M. ARENAS \& I. CRISTINA. 2015a. El conocimiento botánico en zonas urbanas: potenciadores cognitivos comercializados en el Área Metropolitana de Buenos Aires, Argentina. Gaia Scientia 9: 17-31.

HURRELL, J. A., J. P. PUENTES \& P.M. ARENAS. 2015b. Medicinal plants with cholesterol-lowering effect marketed in the Buenos Aires-La Plata conurbation, Argentina: An Urban Ethnobotany study. Ethnobio. Conserv. 4: 7, doi:10.15451/ ec2015-9-4.7-1-19.

INDEC. 2010. Instituto Nacional de Estadística y Censos. Censos Nacionales de Población, Hogares y Viviendas 2001, 2010. Disponible: http://www. indec.gov.ar (Consulta: IV-2016).

INSTITUTO DE BOTÁNICA DARWINION. 2016. Instituto de Botánica Darwinion, Bases de datos. CONICET-ANCEFN. Disponible: http://www. darwin.edu.ar (Consulta: IV-2016).

MARCOS, M. \& G. MERA. 2015. Migrantes internacionales en la Aglomeración Gran Buenos Aires Cuadernos Geográficos 54: 257-282.

MARTIN, G. J. 1995. Ethnobotany. A methods manual. 268 pp. Earthscan, London.

MERA, G. 2014. Migración paraguaya en la Ciudad de Buenos Aires (2010): distribución espacial y pobreza. Rev. Latinoam. Población 8: 57-80.

POCHETTINO, M. L., J. P. PUENTES, F. BUET COSTANTINO, P. M. ARENAS, E. A. ULIBARRI \& J. A. HURRELL. 2012. Functional Foods and Nutraceuticals in a Market of Bolivian Immigrants in Buenos Aires (Argentina). Evid.Based Complem. Alternat. Med. 2012: 320193, doi:10.1155/2012/320193.

PUENTES, J. P. \& J. A. HURRELL. 2015. Plantas andinas y sus productos comercializados con fines medicinales y alimentarios en el Área Metropolitana Buenos Aires-La Plata, Argentina. Bol. Latinoam. Caribe Plant. Med. Aromat. 14: 206-236.

QUINLAN, M. 2005. Considerations for collecting freelists in the field: examples from Ethnobotany. Field Methods 17 (3): 1-16.

RUFFA, M. J., M. L. WAGNER, M. SURIANO, C. VICENTE, J. NADINIC, S. PAMPURO, H. SALOMÓN, R. H. CAMPOS \& L. CAVALLARO. 2004. Inhibitory effect of medicinal herbs against RNA and DNA viruses. Antivir. Chem. Chemother. 15: 153-159.

RUIZ-RUIZ, J. C., Y. B. MOGUEL-ORDOÑEZ \& M. R. SEGURA-CAMPOS. 2015. Biological activity of Stevia rebaudiana and their relationship to health. Crit. Rev. Food Sci. Nutr., doi: 10.1080/10408398.2015.1072083.

SCAVONE, J. C. 2011. Remedios naturales del Paraguay. 103 pp. Servilibro, Asunción. 
STEPP, J. R. 2005. Advances in ethnobiological field methods. Field Methods 17: 211-218.

THE PLANT LIST. 2013. The Plant List. Version 1.1. Royal Botanic Gardens, Kew \& Missouri Botanical Garden. Disponible: http://www.theplantlist.org (Consulta: IV-2016).

TOFFOLI-KADRI, M. C., C. A. CAROLLO, L. DIAS LOURENÇO, J. LOUSADA FELIPE, J. H. BRANDINI NÉSPOLI, L. G. CAMPOS WOLLF , G. M. SOUSA RESENDE, J. RODRIGUES DE LIMA, V. N. PENTEADO FRANCO, M. CARMO VIEIRA \& J. MÁXIMO DE SIQUEIRA. 2014. In vivo and in vitro anti-inflammatory properties of Achyrocline alata (Kunth) DC. J. Ethnopharmacol. 153: 461-468.

TROPICOS. 2016. Tropicos.org. Missouri Botanical
Garden. Disponible: http://www.tropicos.org (Consulta: IV-2016).

UEDA, S., Y. IWAHASHI \& H. TOKUDA. 1991. Production of anti-tumor-promoting iridoid glucosides in Genipa americana and its cell cultures. J. Nat. Prod. 54: 1677-1680.

VISINTINI JAIME, M. F., F. REDKO, L. V. MUSCHIETTI, R. H. CAMPOS, V. S. MARTINO \& L. V. CAVALLARO. 2013. In vitro antiviral activity of plant extracts from Asteraceae medicinal plants. Virol. J., doi: 10.1186/1743-422X-10-245.

ZAPATA, B., C. DURÁN, E. STASHENKO, L. BETANCUR-GALVIS \& A. C. MESA-ARANGO. 2010. Actividad antimicótica y citotóxica de aceites esenciales de plantas de la familia Asteraceae. Rev. Iberoam. Micol. 27: 101-103.

Original recibido el 13 de abril de 2016; aceptado el 5 de mayo de 2006. 